\title{
Empreendedorismo rural: estudo das competências empreendedoras de produtores rurais de leite
}

\section{Rural entrepreneurship: study of entrepreneurial skills of rural milk producers}

\author{
Marisandra da Silva Casali ${ }^{\mathrm{a}}$, Mariana da Silva ${ }^{\mathrm{b}}$, Jessica Casali Turcato ${ }^{\mathrm{c}}$, Daniel Knebel Baggio ${ }^{\mathrm{d}}$, Maria \\ Margarete Baccin Brizolla
}

${ }^{a}$ Mestre em Administração (Universidade Federal de Santa Maria - UFSM/PPGA). Professora do Departamento de Administração, Ciências Contábeis, Economia e Comunicação (DACEC/UNIJUÍ). Ijuí/RS - Brasil. marisandra.casali@unijui.edu.br

${ }^{\text {b} B a c h a r e l ~ e m ~ A d m i n i s t r a c ̧ a ̃ o ~(2018) ~-~ U n i v e r s i d a d e ~ R e g i o n a l ~ d o ~ N o r o e s t e ~ d o ~ E s t a d o ~ d o ~ R i o ~ G r a n d e ~ d o ~ S u l ~(D A C E C / U N I J U I ́) . ~}$ mariana.trevizan21@hotmail.com

${ }^{\mathrm{c}}$ Mestre em Desenvolvimento Regional (UNIJUÍ/PPGDR). Professora Substituta no Instituto Federal Farroupilha Campi Júlio de Castilhos, Eixo de Gestão e Negócios. Cruz Alta/RS - Brasil. jehturcato@hotmail.com. ORCID: http://orcid.org/0000-0003-19826868.jehturcato@hotmail.com

${ }^{\text {d} D o u t o r ~ e ~ M e s t r e ~ e m ~ C o n t a b i l i d a d e ~ e ~ F i n a n c ̧ a s . ~ P r o f e s s o r ~ d o ~ P r o g r a m a ~ d e ~ P o ́ s-G r a d u a c ̧ a ̃ o ~ e m ~ D e s e n v o l v i m e n t o ~ R e g i o n a l ~(U N I J U I) ~}$ e do Programa de Pós-Graduação em Gestão Estratégica de Organizações da Universidade Regional Integrada (URI). Ijuí/RS - Brasil.baggiod@unijui.edu.br

eDoutora em Ciências Contábeis e Administração e Mestre em Ciências Contábeis. Professora do Programa de Pós-Graduação em Desenvolvimento Regional (UNIJUI). Ijuí/RS - Brasil. marga.brizolla@unijui.edu.br

\begin{abstract}
Resumo
As dificuldades enfrentadas pelo setor agropecuário ao longo dos últimos anos refletem em uma readaptação dos produtores rurais. Nesse cenário, o empreendedorismo rural tem ganhado força e requer dos produtores um conjunto de competências para tornar as propriedades viáveis e otimizadas. Com isso, o objetivo deste estudo é analisar as competências empreendedoras dos produtores rurais de leite do Noroeste do Rio Grande do Sul tendo por base o modelo das competências empreendedoras de Lenzi (2008). Trata-se de um estudo quantitativo, descritivo, que utilizou como procedimentos técnicos a pesquisa de campo e como instrumento de coleta um questionário aplicado à 13 produtores. Os resultados demonstram que as 10 competências empreendedoras estão presentes nos produtores pesquisados, com destaque à exigência de qualidade e eficiência (EQE), persistência (PER) e comprometimento (COM), demonstrando que os produtores atuam como empreendedores rurais em suas propriedades. Entretanto, cabem ressalvas ao planejamento e monitoramento sistemático (PMS) e ao estabelecimento de metas (EDM) que não obtiveram resultados tão satisfatórios quanto as demais competências, para essas competências são feitas sugestões de aperfeiçoamento aos produtores.
\end{abstract}

Palavras-chave: Competências; Produtor; Empreendedor; Rural.

\begin{abstract}
The difficulties faced by the agricultural sector over the last years reflect in a readaptation of the rural producers. In this scenario, rural entrepreneurship has gained strength and requires from producers a set of skills to make properties viable and optimized. Thus, the aim of this study is to analyze the entrepreneurial skills of rural dairy farmers in northwestern Rio Grande do Sul based on the entrepreneurial skills model of Lenzi (2008). This is a quantitative, descriptive study that used field research as technical procedures and as a tool to collect a questionnaire applied to 13 producers. The results show that the 10 entrepreneurial skills are present in the surveyed producers, with emphasis on the requirement of quality and efficiency (EQE), persistence (PER) and commitment (COM), demonstrating that the producers act as rural entrepreneurs in their properties. However, there are caveats to the systematic planning and monitoring (PMS) and the setting of goals (EDM) that did not obtain as satisfactory results as the other competences, for these competences suggestions are made to improve the producers.
\end{abstract}

Keywords: Competences; Producer; Entrepreneur; Rural. 


\section{Introdução}

As discussões em torno do agronegócio são de suma importância, especialmente em um país como o Brasil, onde somente o setor agropecuário apresenta crescimento acumulado de 13\% do PIB (Produto Interno Bruto) segundo o último levantamento do Instituto Brasileiro de Geografia e Estatística (Ibge, 2017), representando um papel considerável no desenvolver da economia nacional, e consequentemente no crescimento socioeconômico do País. Contudo, alguns setores vêm enfrentando dificuldades, como é o caso do agropecuário, o qual tem passado por mudanças significativas no decorrer dos últimos anos. A consequência é uma readaptação dos produtores rurais devido ao aumento da competitividade, novas exigências do mercado, falta de regulação de preços e rigidez legislatória em relação a entrada da produção externa no Brasil, ou seja, um conjunto de fatores do ambiente externo que impactam diretamente no negócio de cada um. O reflexo dessa realidade está na produção do setor, ao invés de crescer, houve uma estagnação da produção nos últimos três anos (Ibge, 2017), demonstrando a dificuldade dos produtores de leite em aumentar suas áreas e a produtividade.

Por outro lado, esse conjunto de fatores adversos fez com que o produtor rural buscasse novos modelos de produção, desenvolvendo processos produtivos com custos mais baixos, tornando suas propriedades viáveis e otimizadas. Nesse cenário, o empreendedorismo rural tem ganhado força e espaço com produtores empenhados em manter (ou, até mesmo, aumentar) a produtividade, adequando-se às novas exigências que o mercado propõe. Esses empreendedores também têm buscado o melhor aproveitamento de suas propriedades por meio da implantação de novas atividades que o auxiliem a gerar outras fontes de renda (Endo et al., 2018).

Isso quer dizer que, um empreendedor rural é aquele que transforma suas ideias em realidade aplicando-as na propriedade para seu próprio benefício e, juntamente com as competências empreendedoras que possuir, faz seu empreendimento ser mais competitivo e lucrativo. Callado (2011, p. 53) afirma que o empreendedorismo no agronegócio "contribui de forma significativa para o entendimento de como o empreendedor pode incrementar o grau de competitividade de seu negócio de modo a potencializar sua ação no setor agroindustrial". Para o autor, as competências empreendedoras devem estar alinhadas quando se trata de saber fazer, em saber ser e no saber agir, para auxiliar o empreendedor a decidir quais as ações mais adequadas devem ser tomadas em situações de turbulência no mercado, trazendo agilidade e assertividade na tomada de decisão perante as dificuldades e oportunidades que possam surgir.

Comportamentos empreendedores colaboraram com a diversificação das atividades nas propriedades rurais, buscando a diferenciação e melhorando o desempenho financeiro, uma vez que as receitas auferidas, não dependem unicamente de uma atividade (Endo et al., 2018). Diante do exposto, tem-se o seguinte questionamento: quais as competências empreendedoras identificadas nos produtores rurais de leite do Noroeste do Estado do Rio Grande do Sul? Para responder essa pergunta, este estudo analisa as competências empreendedoras presentes nos produtores rurais de leite do Noroeste do Rio Grande do Sul.

Oliveira et al. (2018) buscaram identificar características empreendedoras em 23 produtores de castanha de caju em Serra do Mel/RN. Endo et al. (2018) verificaram as motivações de um produtor rural para escolher a diversificação de culturas em sua propriedade localizada no Oeste de São Paulo. Bracht \& Werlang (2015), identificaram as competências empreendedoras em produtores rurais catarinenses, o qual utilizou escala likert de 5 pontos para o modelo de Lenzi (2008). Nesse sentido este estudo busca identificar competências empreendedoras em produtores de leite do Noroeste do Estado do Rio Grande do Sul, sendo que a principal diferença deste estudo para os demais apresentados está na amostra, o que se constitui na lacuna de 
pesquisa, justificando a realização deste estudo.

\section{Referencial teórico}

\subsection{Empreendedorismo rural e competências empreendedoras}

Empreendedorismo para Reis e Armond (2012, p. 1), é "Uma palavra relativamente simples que esconde um conceito muito poderoso, move a economia mundial e permite as pessoas realizarem seus sonhos e mudarem o mundo para melhor.”. Os empreendedores são pessoas que se destacam no meio da multidão, querem ser reconhecidas pelo seu trabalho, são extremamente apaixonadas pelo que fazem, estão sempre na busca do novo, são os principais responsáveis em eliminar barreiras comerciais e culturais, criam novos conceitos de trabalho, quebram paradigmas, e geram riqueza para a sociedade (Dornelas, 2012).

Vale, Corrêa e Reis (2014), ao analisar as motivações para o empreendedorismo, constataram que os motivos que levam as pessoas a empreenderem ultrapassam a dicotomia entre necessidade versus oportunidade, e incluem motivações como oportunidades, atributos pessoais, mercado de trabalho, insatisfação com o emprego, família e influência interna.

Estudos recentes (Müller \& Korsgaard, 2018; Muñoz \& Kimmitt, 2019) têm centrado a análise na importância do contexto espacial e socioespacial para as atividades empreendedoras e processos empresariais. Müller e Korsgaard (2018) constataram que os recursos locais e a ligação espacial são aspectos que influenciam nas atividades empresariais e, por consequência, no desenvolvimento do espírito empreendedor, uma vez que, os empresários estão enraizados nos seus contextos locais, influenciando as decisões sobre o que produzir, com quem colaborar, quem contratar e quais os mercados servir. Esse contexto espacial viabiliza aos empreendedores um conjunto de recursos materiais e imateriais finitos, a partir dos quais os empreendedores podem criar novas combinações, denominados de toolkit por Swidler (1986).

Muñoz e Kimmit (2019), pela lente socioespacial, resgatam a ação e as interações humanas associadas com as dinâmicas sociais e materiais, características e história do lugar, as quais explicam como os empresários rurais e outros atores podem ser encorajados a assumir incertezas e financiar novos negócios.

Moraes, Iizuka e Pedro (2018) investigaram os efeitos das características empreendedoras e do ambiente universitário na intenção empreendedora dos universitários, constatando que, a intenção empreendedora dos estudantes é influenciada pelo ambiente universitário, pela atitude em relação a assumir riscos e pela autoeficácia, a qual é reflexo das características de planejador, liderança e inovador desses estudantes. A análise demonstra a importância da educação empreendedora e dos discussões dessa temática para o desenvolvimento de empreendedores.

Apesar do cenário apresentado, Sertek (2007, p. 18), antecedentemente, afirma que "A riqueza dos empreendimentos depende, sobretudo das pessoas que as empreendem, e no século XXI, não basta somente intuição é preciso competência". Para isso, o autor comenta que é preciso que os empreendedores aprimorem suas competências que são um conjunto de conhecimento, habilidade e atitude.

A empresa rural é uma organização ou produtor que explora a capacidade produtiva do solo, sendo pelo cultivo da terra, ou na criação de animais, tudo isso com o propósito de obter renda/lucro, e dessa forma por ter esses aspectos a empresa rural não se difere das outras organizações. Com isso, pode se dizer que o produtor rural passou a ser um empreendedor quando começou a trabalhar diretamente na fabricação e comercialização dos seus produtos gerados em suas propriedades, obtendo renda que mantem sua propriedade e a sustentação 
de sua família (Callado, 2011; Endo et al., 2018).

Para que a propriedade rural se perpetue ao longo das gerações, é necessário que os empreendedores rurais não fiquem acomodados, eles devem buscar conhecimento, incorporar novidades em suas propriedades, ter consciência e humildade quando precisar de ajuda e não se incomodar em ir buscar (Caetano, 2014; Endo et al., 2018).

O Brasil tem alcançado uma posição de liderança como produtores e fornecedores de alimentos e fibras para o mundo, esse resultado é uma combinação de investimentos em tecnologia, pesquisas, extensão territorial útil à agricultura e à pecuária, clima favorável, integração de cadeias produtivas, e a capacidade empreendedora (Callado, 2011; Oliveira et al., 2018). Nesse sentido, Dutra (2001) compreende competência como um conjunto de conhecimentos, habilidades e atitudes necessárias que o indivíduo deve ter para desenvolver suas atribuições e reponsabilidades e quando presentes nas pessoas permitem um padrão de desempenho superior na execução de determinados trabalhos.

Essas competências também conhecidas como CHA sendo elas: a) conhecimento: é o saber, são conhecimentos que o indivíduo adquire no decorrer de sua vida, através da busca de aumentar seus conhecimentos na escola, universidade, cursos, palestras entre outros; b) habilidade: o saber fazer, quando o indivíduo não apenas possui o conhecimento e sim sabe aplicá-los, em saber exercer uma tarefa ou atividade com facilidade e aptidão; e, c) atitude: saber ser e agir, ao querer fazer, o indivíduo possui um comportamento de iniciativa diante de situações que ocorrem em seu dia a dia como dificuldades ou desafios, não espera que as coisas aconteçam ou que outra pessoa o faça e sim ele o faz por conta própria (Dutra, 2001).

Assim, por meio da aplicação das competências, a pessoa vai estimular o desenvolvimento profissional, habilidades-chaves, multifuncionalidade, mas também estimula a produção de ações de geração de valor (Dutra, 2001; Bracht \& Werlang, 2015). A noção de competência agrega valor econômico à organização e também agrega valor social ao indivíduo, ou seja, quando a pessoa desenvolve as competências está investindo em si mesma não só como cidadão organizacional, mas como cidadão do próprio país e do mundo (Fleury \& Fleury, 2004).

Para Resende (2008, p. 10), o significado de competência pode ser definido, entre outras maneiras, "como uma força motriz do autodesenvolvimento pessoal, profissional e social. Ela tem o poder de efetivar, energizar e ampliar a aplicação das inteligências que desenvolvemos e dos conhecimentos que adquirimos". $\mathrm{O}$ autor relata que todas as pessoas desenvolvem competências ao longo da vida, porem muitas vezes não é aplicado de forma correta e nem na sua totalidade, com isso as pessoas desperdiçam um bem muito precioso. É importante que todas as pessoas até mesmo empresas e organizações se dediquem em identificar, desenvolver e aplicar melhor suas competências.

A indústria brasileira está passando por importantes modificações, devido a fatores internos e externos, e é a formação das competências que cria as condições para o desenvolvimento sustentado, é a forma como as competências são administradas que vão, por sua vez, influenciar nas estratégias competitivas (Fleury \& Fleury, 2004; Endo et al., 2018). Nesse cenário, as competências empreendedoras constituem um conjunto amplo de competências necessárias que um empreendedor deve possuir para iniciar seu novo negócio e fazer com que seu empreendimento cresça, tendo um desempenho superior diferenciado, essas competências empreendedoras não podem ser vistas isoladamente e sim em conjunto, obtendo, dessa forma, seu caráter multifuncional e integrado (Callado, 2011; Oliveira et al., 2018).

Lenzi (2008) desenvolveu um instrumento para identificar as competências empreendedoras, dividido 
em três categorias principais com suas competências empreendedoras, conjunto de realizações (busca de oportunidade, correr riscos calculados, exigência de qualidade e eficiência, persistência e comprometimento), conjunto de planejamento (busca de informação, estabelecimento de metas, e planejamento e monitoramento sistemático) e conjunto de poder (persuasão e rede de contatos, independência e autoconfiança).

Por meio desse instrumento, é possível perceber que um indivíduo com competências individuais bem definidas pode utiliza-las para ações empreendedoras, porém não adianta apenas o indivíduo possuir tais competências é necessário que busque o espaço adequado para aplica-las e fazer gerar resultados, as competências empreendedoras devem ter um foco bem definido na busca de resultados por parte do profissional em prol da empresa (Lenzi, 2008).

\section{Método}

Para atender o objetivo proposto de identificar as competências empreendedoras identificadas nos produtores rurais de leite do Noroeste do Estado do Rio Grande do Sul. Enquadra-se como uma pesquisa descritiva, visto que tais pesquisas expõem características de determinada população ou de determinado fenômeno (Triviños, 1987). Quanto aos procedimentos técnicos utilizados se tratou de uma pesquisa de campo, sendo realizado uma investigação in loco (na propriedade) para identificar as competências empreendedoras dos pesquisados (Triviños, 1987). Utilizou-se também a pesquisa quantitativa, em razão da quantificação da pontuação (Richardson, 1999). Os dados foram coletados a partir do uso de um questionário com perguntas fechadas, individuais e em cada propriedade estudada, tendo como base o modelo de Lenzi (2008).

\section{CONJUNTO DE REALIZAÇÃO}

\section{BUSCA DE OPORTUNIDADES E INICIATIVA (BOI)}

1) Lidera ou executa novos projetos, ideia e estratégia que visam conceber, reinventar, produzir ou comercializar novos produtos ou serviços.

2) Toma iniciativas pioneiras de inovação gerando novos métodos de trabalho, negócio, produtos ou mercados para empresa.

3) Produz resultados para a empresa decorrente da comercialização de produtos e serviços gerados da oportunidade de negócio que identificou e captou no mercado.

\section{CORRER RISCOS CALCULADOS (CRC)}

1) Avalia o risco de suas ações na empresa ou no mercado por meio de informações coletadas.

2) Age para reduzir os riscos das ações propostas.

3) Está disposto a correr riscos, pois eles representam um desafio pessoal e poderão de fato trazer bom retorno para a empresa EXIGÊNCIA DE QUALIDADE E EFICIÊNCIA (EQE)

1) Suas ações são muito inovadoras, trazem qualidade e eficácia nos processos.

2) É reconhecido por satisfazer seus clientes internos e externos por meio de suas ações e resultados.

3) Estabelece prazos e os cumpre com padrão de qualidade reconhecido por todos.

\section{PERSISTENNCIA (PER)}

1) Age para driblar ou transpor obstáculos quando eles se apresentam.

2) Não desiste em situações desfavoráveis e encontra formas de atingir os objetivos.

3) Admite ser responsável por seus atos e resultados, assumindo a frente para alcançar o que é proposto.

\section{COMPROMETIMENTO (COM)}

1) Conclui uma tarefa dentro das condições estabelecidas, honra os patrocinadores e parceiros internos.

2) Quando necessário, "coloca a mão na massa" para ajudar a equipe a concluir um trabalho.

3) Está disposto a manter os clientes (internos e externo) satisfeitos e de fato consegue.

1) Vai pessoalmente atrás de informações confiáveis para realizar um projeto. 
2) Investiga pessoalmente novos processos para seus projetos ou ideias inovadoras.

3) Quando necessário, consulta pessoalmente especialistas para lhe ajudar em suas ações.

ESTABELECIMENTO DE METAS (EDM)

1) Define suas próprias metas, independente do que é imposto pela empresa.

2) Suas metas são claras, específicas e entendidas por todos os envolvidos.

3) Suas metas são mensuráveis e perfeitamente acompanhadas por todos da equipe.

\section{PLANEJAMENTO E MONITORAMENTO SISTEMÁTICO (PMS)}

1) Elabora planos com tarefas e prazos bem definidos e claros.

2) Revisa constantemente seus planejamentos, adequando-os quando necessários.

3) É ousado na tomada de decisões, mas se baseia em informações e registros para projetar resultados

CONJUNTO DE PODER

\section{PERSUASÃO E REDE DE CONTATO (PRC)}

1) Consegue influenciar outras pessoas para que sejam parceiros em seus projetos viabilizando recursos necessários para alcançar os resultados propostos.

2) Consegue utilizar pessoas chave para atingir os resultados que se propõe ou conseguir os resultados necessários

3) Desenvolve e fortalece sua rede de relacionamento interno e externo à empresa.

\section{INDEPENDÊNCIA E AUTOCONFIANÇA (IAC)}

1) Está disposto a quebrar regras, suplantar barreiras e superar obstáculos já enraizados na empresa.

2) Confia em seu ponto de vista e o mantém mesmo diante de oposições.

3) É confiante nos seus atos e enfrenta desafios sem medo.

Quadro 1. Competências Empreendedoras.

Fonte: Lenzi (2008, p. 47).

O instrumento foi constituído de 30 questões que permitem a identificação das dez competências empreendedoras, cada uma das competências possuem 3 questionamentos com o máximo de 5 pontos cada, totalizando 15 pontos por competência. Cada uma das 3 questões é pontuada em uma escala likert de 1 a 5 pontos, sendo 1 para presença muito fraca do comportamento e 5 para presença muito forte. Para que haja competência empreendedora na avaliação do indivíduo é necessário que obtenha 12 pontos, os quais indicam a presença da competência empreendedora, destacando que a pontuação máxima é de 15 pontos.

O universo da amostra são treze propriedades familiares produtoras de leite, nos municípios de Catuípe, Chiapetta, Ijuí, Inhacorá e Jóia. A amostra não é probabilística, pois não se utilizaram procedimentos estatísticos, e sim por acessibilidade, pelo fato de o pesquisador ter facilidade acesso aos participantes. Os participantes da pesquisa foram os proprietários produtores de leite, os quais foram entrevistados no período de agosto à novembro do ano de 2018.

\begin{tabular}{|l|c|c|}
\hline \multicolumn{1}{|c|}{ GRUPO } & VACAS ORDENHADAS (CABEÇA) & PRODUTORES (N ${ }^{\boldsymbol{}}$ ) \\
\hline P & Até 10 & 4 \\
\hline M & De $11-14$ & 5 \\
\hline G & De $15 \mathrm{ou}+$ & 4 \\
\hline TOTAL & & 13 \\
\hline
\end{tabular}

Quadro 2. Classificação por grupo.

Fonte: Autores.

Quanto à análise e interpretação dos dados coletados, os dados foram tabulados pelo software Excel. As tabelas apresentam valores como média, valores mínimos e máximos, frequências e porcentagem dos resultados. Para uma melhor análise, a partir da amostra dos 13 produtores rurais de leite foi criado três grupos 
(pequeno, médio e grande) conforme o número de vacas ordenhadas, apresentados no Quadro 2.

\section{Análise e discussão dos resultados}

Buscou-se nessa etapa a partir das respostas obtidas com o instrumento, verificar as competências empreendedoras dos produtores rurais de leite do noroeste do RS, sendo observados e apresentados os resultados a respeito das 10 competências empreendedoras dos produtores rurais de leite.

\subsection{Competências empreendedoras dos produtores rurais}

O instrumento de pesquisa desenvolvido por Lenzi (2008) permite tal identificação pela presença das competências: BOI (Busca de oportunidades e iniciativa); CRC (Correr riscos calculados); EQE (Exigência de qualidade e eficiência); PER (Persistência); COM (Comprometimento); BDI (Busca de informação); EDM (Estabelecimento de metas); PMS (Planejamento e monitoramento sistemático); PRC (Persuasão e rede de contatos); e, IAC (Independência e autoconfiança).

O Quadro 3 apresenta a distribuição do resultado dos 13 produtores pesquisados em cada uma das 10 competências. Para que haja a presença de alguma competência deve-se obter pontuação acima de 12 pontos, desse modo, observa-se a concentração de competências empreendedoras nas linhas de 12 a 15 pontos, confirmando assim a presença das 10 competências na amostra pesquisada.

Percebe-se no Quadro 3, as competências que não atingiram a pontuação necessária, ou seja, obtiveram uma pontuação abaixo de 12 pontos, apresentadas nas linhas em branco de 1 a 11 . Sendo que para a busca por oportunidade (BOI), tem-se respondente com 6, 8, 9 pontos e dois com 11 pontos, dessa forma 38\% dos investigados não possuem tal competência empreendedora. Os resultados de Endo et al. (2018) identificaram essa competência em $50,89 \%$ dos pesquisadas.

$\mathrm{Na}$ competência, correr riscos calculados (CRC), apenas três produtores não atingiram 12 pontos que é o necessário de acordo com o modelo, para que a competência seja percebida, esse número representa $23 \%$ dos respondentes. Destes, tem-se 5, 8 e 10 pontos, isto é, essa competência está presente em $77 \%$ dos respondentes. Tal indicativo é superior ao encontrado no estudo de Endo et al. (2018), o qual identificou essa competência em $46 \%$ da amostra investigada.

\begin{tabular}{|c|c|c|c|c|c|c|c|c|c|c|}
\hline $\begin{array}{l}\text { Competência/ } \\
\text { Pontuação }\end{array}$ & 01 BOI & 02 CRC & $03 \mathrm{EQE}$ & 04 PER & 05 СОМ & 06 BDI & 07 EDM & 08 PMS & 09 PRC & 10 IAC \\
\hline \multicolumn{11}{|l|}{1} \\
\hline \multicolumn{11}{|l|}{2} \\
\hline 3 & & & & & & & & 1 & & \\
\hline \multicolumn{11}{|l|}{4} \\
\hline 5 & & 1 & & & & & & & 1 & \\
\hline 6 & 1 & & & & & & & & & \\
\hline 7 & & & & & & 1 & & 1 & & \\
\hline 8 & 1 & 1 & & & & & 1 & 2 & & \\
\hline 9 & 1 & & & & & & 1 & 1 & & \\
\hline 10 & & 1 & 1 & 1 & & 1 & 2 & 1 & 1 & 1 \\
\hline 11 & 2 & & & & 1 & 3 & 4 & 1 & 2 & 3 \\
\hline 12 & 1 & 4 & 2 & 1 & & 3 & 3 & 1 & 2 & 5 \\
\hline 13 & 4 & 6 & 4 & 3 & 4 & & 2 & 1 & 3 & 2 \\
\hline 14 & 1 & & 4 & 4 & 5 & 4 & & 2 & 3 & 2 \\
\hline 15 & 2 & & 2 & 4 & 3 & 1 & & 2 & 1 & \\
\hline
\end{tabular}




\begin{tabular}{|l|l|l|l|l|l|l|l|l|l|l|}
\hline Total & 13 & 13 & 13 & 13 & 13 & 13 & 13 & 13 & 13 & 13 \\
\hline
\end{tabular}

Quadro 3. Distribuição das competências por pontuação individual dos produtores.

Fonte: Autores

A competência, exigência de qualidade e eficiência (EQE), está entre as mais bem colocadas nesta análise, onde apenas $8 \%$ dos respondentes não atingiram 12 pontos, sendo que um respondente atingiu 10 pontos. Outra competência que teve $8 \%$ abaixo dos 12 pontos é a persistência (PER) com um produtor com 10 pontos. Também com $8 \%$ abaixo de 12 pontos, tem-se a competência comprometimento (COM), em que o respondente apresentou 11 pontos. Essas três competências têm relação direta com a atividade executada pelos produtores, sendo de suma importâncias suas contribuições, a aplicações destas competências influenciam em todo o processo de produção na propriedade, principalmente no retorno financeiro (Endo et al., 2018), por isso é possível compreender por que apenas 1 produtor não atingiu 12 pontos em cada uma dessas três competências.

Nesse sentido para essas competências, Endo et al. (2018) encontraram para a exigência de qualidade e eficiência (EQE), presentes em 64,97\%, a persistência (PER) presente em 87,42\% dos respondentes e a competência comprometimento (COM), presentes em 79,94\% dos respondentes.

Com 38\% abaixo de 12 pontos a competência busca por informação (BDI) apresenta um respondente com 7 pontos, um com 10 pontos e três atingiram 11 pontos, indicando que 5 dos 13 respondentes não possuem esta competência. Este resultado é superior ao encontrado por Endo et al. (2018), quais identificaram essa competência em $25,45 \%$ dos produtores pesquisados.

O estabelecimento de metas (EDM) possui 8 produtores que não atingiram 12 pontos, cerca de $62 \%$, sendo a competência que está menos está presente na amostra, esse dado causa preocupação, pois essa competência juntamente com as demais ajudam o indivíduo a se tornar um empreendedor e transformar o seu negócio no sucesso que tanto almeja, independentemente do ramo da atividade que é exercida. No planejamento e monitoramento sistemático (PMS) um produtor atingiu somente 3 pontos, um com 7 pontos, dois atingiram 8 pontos, um atingiu 9 pontos, outro indivíduo com 10 pontos, e um com 11 pontos, dando um total de 7 indivíduos que não atingiram 12 pontos sendo $53 \%$.

Endo et al. (2018) constataram a competência estabelecimento de metas (EDM), presente em 63,17\% de respondentes e a competência planejamento e monitoramento sistemático (PMS), está presente em 46\% dos respondentes.

Percebe-se para a competência de persuasão e rede de contatos (PRC) possui 4 produtores que não atingiram 12 pontos, na qual um produtor atingiu 5 pontos, um com 10 pontos e dois com 11 pontos. Também com 4 produtores que não atingiram 12 pontos está a independência e autoconfiança (IAC), onde um produtor pontuou 10 pontos e três com 11 pontos. Sendo que para esses produtores que não atingiram os 12 pontos, indicando que esses indivíduos não possuem tais competências, no total da amostra corresponde a 30\%. De acordo com o estudo de Endo et al. (2018), essas competências (PRC e AIC) estavam presentes em 69,46\% dos respondentes.

A Tabela 1 apresenta as competências empreendedoras que atingiram a pontuação de 12 pontos, demonstrando quais estão mais frequentes nos produtores, ou seja, apontando as maiores e menores frequências de presença das competências de cada um dos 13 respondentes. 
Tabela 1

Competências empreendedoras com pontuação obtida de 12 pontos.

\begin{tabular}{ccc}
\hline Competências & Frequências & Porcentagem \\
\hline EQE & 12 & $92 \%$ \\
PER & 12 & $92 \%$ \\
COM & 12 & $92 \%$ \\
CRC & 10 & $77 \%$ \\
PRC & 9 & $70 \%$ \\
IAC & 9 & $70 \%$ \\
BOI & 8 & $62 \%$ \\
BDI & 8 & $62 \%$ \\
PMS & 6 & $47 \%$ \\
EDM & 5 & $38 \%$ \\
\hline
\end{tabular}

a) Em primeiro destaque com $92 \%$ se encontra o conjunto de competências, exigência de qualidade e eficiência (EQE); persistência (PER); comprometimento (COM).

As atividades realizadas pelos produtores como a venda do leite, possuem uma vasta exigência de normas de qualidade que o produtor deve aderir, que por sua vez influencia no preço pago pelo produto, assim, quanto maior a qualidade, maior o preço pago pelo produto. Desse modo, percebe-se porque a exigência de qualidade e eficiência está entre a mais presentes nos produtores.

Aguiar (2013) relata que a busca pela qualidade e pela eficiência do empreendimento faz com que o empreendedor mantenha os clientes conquistados e se diferencie dos concorrentes, a máxima qualidade nos produtos garante a fidelidade dos seus consumidores. $\mathrm{O}$ empreendedor deve sempre buscar em satisfazer ou superar as expectativas de prazos e padrões de qualidade.

A persistência (PER) está presente diariamente na vida dos produtores, pois as atividades elaboradas por eles necessitam de muita persistência para alcançar os objetivos desejados. É através da persistência que os produtores enfrentam desafios, como a queda no preço do leite, a seca que danifica o pasto, o aumento do preço dos insumos que compõem a alimentação do rebanho, a perda de animais, o clima, entre outros. A persistência é de grande importância para que o produtor atinja o sucesso de seu empreendimento, ao ser persistente e não desistir ou desanimar apesar das dificuldades que enfrentam.

Para Castanheira (2014) não existe formula, receita ou regras que façam o indivíduo em possuir a persistência, porem relata que ela é essencial para o desenvolvimento de um negócio. Castanheira compara os empreendedores aos melhores atletas, pois ambos são capazes de resistir a dor e de se superar, em transformar as derrotas em energias que vai movê-los para a próxima vitória, capacidade de não desanimar perante as adversidades.

O comprometimento $(\mathrm{COM})$ também é bem forte na presença do dia a dia dos produtores, a rotina de trabalho do produtor rural se baseia nos 7 dias da semana, de segunda à segunda, para eles não existe folga ou feriado, sua atividade começa cedo da manhã e se estende durante o dia todo sem horário definido para o fim de suas atividades. O comprometimento com os animais resulta 24 horas por dia, pois sempre pode ter um animal doente que podem necessitar de ajuda e medicamentos. Na empresa rural é necessário que o produtor esteja completamente comprometido com todas as funções que envolvem as atividades na propriedade, caso contrário, pode ocorrer o não alcance do sucesso que almeja.

Segundo Aguiar (2013), o comprometimento é quando os empreendedores devem manter suas promessas, não importa quão grande seja o sacrifício pessoal. Deve-se comprometer com a qualidade do produto 
vendido, ter honestidade, fazer sacrifícios para completar suas tarefas, é o envolvimento do empreendedor pelo seu negócio de corpo e alma.

\section{b) Com $77 \%$ a competência correr riscos calculados (CRC).}

Esse dado demonstra que os produtores estão cientes dos riscos de suas decisões podem ocasionar. É necessário que os produtores avaliem bem suas decisões, analisar quais são os riscos para que não afete significativamente a vida de seu empreendimento. É através de novas ideias que surgem melhorias no negócio, por isso que é essencial que haja uma visão de todo o cenário que o negócio se encontra, assim é possível analisar os riscos que perpassa uma empresa rural e com isso não ocorra prejuízos e danos na empresa.

O correr riscos calculados, segundo Aguiar (2013), é o quanto o empreendedor está disposto a assumir desafios ou riscos moderados e responder pessoalmente por eles. Para isso, é necessário calcular tais riscos, o empreendedor não deve corres riscos aleatórios, mas sim deve usar a cabeça e o lápis para calcular até onde pode ir. O empreendedor precisa ter em mente que o risco existe, mas conhecendo o mercado e seu potencial será capaz de avaliar se o passo que está dando é proporcional ao seu tamanho, isto é tomar uma decisão racional.

c) Persuasão e rede de contatos (PRC); independência e autoconfiança (IAC) atingiram 70\% entre os respondentes.

Através da persuasão, os produtores podem convencer outras pessoas a tomarem uma atitude que lhe convêm, está em persuadir os demais membros da atividade leiteira a aceitarem sua ideia, para isso é essencial que o líder saiba persuadir outras pessoas com o intuito que elas sigam as suas instruções. Fazendo o uso adequado de sua rede de contato, os produtores podem usufruir de diversas oportunidades, pois a rede de contato serve para compartilhar informações, um meio de troca de ideias, não importa a quantidade de pessoas que estão conectadas, mas sim a qualidade destes contatos.

Dornelas (2012) relata que os empreendedores devem saber construir uma boa rede de contatos para que os auxiliem no ambiente externo da empresa, junto a clientes, fornecedores e parceiros estratégicos.

A independência e autoconfiança (IAC) demonstra como os produtores possuem segurança em suas atitudes na busca de seus objetivos, em enfrentar os obstáculos que encontram em sua trajetória. É quando o produtor acredita e confia em suas habilidades, estando seguro na decisão que tomou. Quando o produtor é autoconfiante tem mais chances de atingir metas e objetivos, pois avança sem medo dos desafios, tem determinação e acredita que vai conseguir alcançar seus sonhos.

d) A busca por oportunidades e iniciativa (BOI); a busca de informação (BDI) essas duas competências atingiram $62 \%$ de presença nos respondentes.

A busca por oportunidades e iniciativa no ramo do agronegócio é de suma importância, pois surgem diariamente novas formas de tecnologias que facilitam a vida no campo, como máquinas, implementos, acessórios, insumos, entre outros que possuem como principal objetivo o aumento da produtividade na propriedade rural. Desse modo, os produtores devem sempre ir em busca de novas oportunidades e iniciativas para que possam ampliar ou melhorar o seu negócio, para que haja uma melhor produtividade, porém, cabe ao produtor analisar qual oportunidade é viável em seu empreendimento, muitas vezes o investimento é alto, mas o retorno obtido é compensatório.

Para Aguiar (2013), os empreendedores devem possuir uma capacidade de se antecipar aos fatos e de criar oportunidades de negócios, desenvolver produtos e serviços, também em propor soluções inovadoras. É quando o empreendedor desenvolve a capacidade de entender o que acontece ao redor de seu negócio, 
fazendo com que a cabeça do empreendedor crie as oportunidades ao invés de simplesmente esperar por elas. O empreendedor sempre deve estar à procura de oportunidades únicas e toma a iniciativa para transforma-las em situações de negócio.

Em qualquer meio de negócio, a informação é essencial na busca do sucesso, sendo assim os produtores devem sempre ir em busca de informações e, principalmente, se especializar na atividade que desenvolvem. Para isso, é importante que os produtores participem de cursos, palestras, feiras ou reuniões onde aconteça a troca de conhecimento e informações, para que posso aplicar tais informações adquiridas na propriedade, fazendo com que seu negócio se torne um diferencial entre os outros, se adaptando com mais facilidade a futuras mudanças que o mercado exigir, ou até mesmo auxiliar na tomada de decisões.

Conforme Dornelas (2012), os empreendedores devem ser sedentos pelo saber e buscarem aprender continuamente, porque sabem que quanto maior o domínio sobre o seu negócio maior será a chance de êxito, tais conhecimentos podem vir da própria experiência prática ou de informações que são obtidas em publicações especializadas, ou adquiridas através de cursos, palestras que envolvem o ramo do negócio exercido.

e) Em quinta posição com 47\%, a competência de planejamento e monitoramento sistemático (PMS).

O planejamento para qualquer atividade de negócio é de suma importância, é através do planejamento que se pode guiar o rumo desejado da empresa. Com o planejamento se pode definir quais são os principais objetivos a serem alcançados, por quais meios serão atingidos esses objetivos e as metas que deveram ser compridas.

Possuindo um planejamento, o produtor pode utilizar tal planejamento na tomada de decisão, sendo também necessário o uso deste meio em determinadas situações, como na hora de implementar novas ideias, para ampliação do empreendimento, compra de novos equipamentos, utilização correta da renda, servindo também para análise da situação real que a propriedade se encontra.

Segundo Dornelas (2012), os empreendedores de sucesso planejam cada passo de seu negócio, sempre tendo como base a forte visão de negócio que possuem. O diferencial do empreendedor de sucesso é o uso constante de planejamento, pois a partir disso se cria uma visão do futuro que deseja alcançar em seu empreendimento.

f) A competência que possui menos presença nos respondentes com 38\% é o estabelecimento de metas (EDM), onde apenas 5 produtores possuem está competência.

O estabelecimento de metas auxilia os produtores a traçar o caminho que desejam percorrer. Para isso, é fundamental que o produtor se organize e se comprometa com todos os objetivos que estipular, para melhor compreensão o produtor deve utilizar de anotações onde estão elencadas todas as suas metas a serem atingidas e segui-las à risca sem perder o foco. Também, é importante o envolvimento de todos os integrantes da atividade nestas metas, assim fazendo com que eles estejam comprometidos com o negócio. Para o desenvolvimento de metas é importante que o produtor crie de forma que seja específica e principalmente alcançável, podendo ser mensais como anuais.

Segundo Aguiar (2013), o estabelecimento de metas é a competência mais importante, porque nenhuma das outras vai funcionar sem um estabelecimento de metas claras, bem definidas e que possuem um prazo de início e término, e devem representar desafios, ser ousadas, divididas em curto e longo prazo. $\mathrm{O}$ estabelecimento de metas funciona como um processo motivacional porque ajuda a criar um parâmetro entre o desenvolvimento atual e o desempenho desejado, contribui com a autoestima e estimula mais ainda as necessidades de crescimento pessoal, os empreendedores que alcançam de maneira bem-sucedida suas metas 
tendem a estabelecer metas ainda mais elevadas.

\subsection{Sugestões de aperfeiçoamento das competências}

Onde apenas 5 produtores atingiram 12 pontos que denotam a presença da competência de estabelecimento de metas (EDM) é proposto para os demais produtores a implementação de metas em sua rotina rural. Primeiramente o indivíduo deve ter em mente o que quer atingir, qual objetivo deseja alcançar, em seguida deve descrever o caminho a ser percorrido (metas), como deve proceder para alcançar o objetivo. O ideal é escrever as metas em anotações visíveis, desse modo o produtor terá sempre em mente o foco do percurso que deverá percorrer para chegar no destino. As metas quando aplicadas no dia a dia servem como motivadoras, sendo que quando alcançadas o indivíduo se sente realizado e motivado em seguir em frente, assim estabelecendo metas mais desafiadoras.

No planejamento e monitoramento sistemático (PMS) pode-se sugerir a utilização de anotações mensais, que podem ocorrer em cadernos ou em planilhas do Excel, tais anotações auxiliam o produtor a controlar melhor seus gastos, tendo uma visão das entradas e saídas que ocorrem na propriedade, dessa forma podendo observar o real faturamento que ocorre na atividade leiteira. Essas anotações auxiliam na tomada de decisão, também fazem com que o produtor possa corrigir despesas desnecessárias que sem a utilização destas anotações não teria como serem identificadas.

Para a busca de informações (BDI) sugere-se para o produtor a troca de conhecimento entre si, com vizinhos, amigos que praticam a mesma atividade, também a participação em feiras e eventos relacionados a produção leiteira, cursos, ou a busca por auxílio de consultoria em entidades de ensino como a Sebrae, também disponibilizando a sua propriedade para alunos da Unijuí para aplicarem pesquisas que proporcionam sugestões de melhorias no processo da produção leiteira.

Propõe-se para os produtores em aperfeiçoar a competência de busca de oportunidade e iniciativa (BOI) a participação em associações, pois quando é sócio dessa entidade o produtor adquire de várias oportunidades, como a utilização de financiamentos mais viáveis, melhorias da infraestrutura, compra mais acessíveis de máquinas, melhorias na genética do rebanho, e principalmente usufrui de uma maior rentabilidade do litro do leite pago. Pois quando se trata de uma associação, a quantidade de leite disponível é grande, gerando assim um interesse das empresas industrializadoras de leite. Com esse ganho maior os associados podem obter um acompanhamento de um profissional da área da saúde e bem-estar animal para o monitoramento e prevenções de doenças.

\section{Considerações finais}

Esta pesquisa foi desenvolvida para responder a inquietação em compreender quais eram as competências empreendedoras identificadas nos produtores rurais de leite do Noroeste do Estado do Rio Grande do Sul, para suprir essa questão o principal objetivo do estudo foi a identificação das competências empreendedoras nos produtores rurais de leite distribuídos em cinco municípios do interior do noroeste do estado do Rio Grande do Sul. Assim, com base nos resultados da pesquisa, foi possível identificar as 10 competências empreendedoras nos 13 produtores participantes da investigação, sendo que as competências com maior destaque são a exigência de qualidade e eficiência (EQE), persistência (PER) e comprometimento (COM) que possuem $92 \%$ de presença entre os respondentes, onde apenas 1 produtor não possui essas 3 competências. Esses dados demonstram que estas competências com grande destaque podem ser fundamentais 
para a realização e execução de ações com características empreendedoras na empresa rural.

No entanto, embora todas as competências tenham sido identificadas entre os produtores, as de PMS (planejamento e monitoramento sistemático) e de EDM (estabelecimento de metas) não obtiveram um resultado satisfatório. Sabe-se que, para que o empreendimento atinja o sucesso, é necessário que o indivíduo exerça todas essas competências empreendedoras, mas por se tratar de um negócio diferenciado faz com que o agricultor desenvolva características específicas que condizem com a atividade que elabora, também, esse setor influencia no surgimento de dificuldades distintas dos demais segmentos de negócio e com isso é condizente com a baixa existências dessas duas competências.

Em seguida, foi possível identificar o perfil e as atividades elaboradas pelos produtores, como resposta aos demais objetivos deste estudo, assim é notável o quanto esses produtores se empenham em sua propriedade com o intuito de oferecer o melhor para a sua família, adquiriram resistência em enfrentar desafios específicos que está atividade propõem, mas apesar de todos os obstáculos, 92\% destes produtores respondentes vão permanecer nesta atividade firmes e fortes, e com o desejo de melhorar continuamente para atingir os resultados desejados por eles, que é o aumento da lucratividade de sua propriedade.

É por esses produtores que é possível relacionar as competências empreendedoras com o termo de empreendedorismo rural, no entanto, é necessário que ocorra uma preocupação dos produtores em aprimorar as competências que não estão presentes em sua atividade para que haja um melhor desenvolvimento da agricultura leiteira nas pequenas propriedades e, assim, chamando a atenção de órgãos que possam auxiliar e oferecer melhores benefícios nesta atividade, pois este negócio ajuda no desenvolvimento socioeconômico da região onde estão localizados, direta e indiretamente.

Outra questão necessária em ser relatada diz respeito às dificuldades enfrentadas na produção leiteira, como já mencionado anteriormente a atividade enfrenta inúmeras dificuldades, porém, a mais pronunciada pelos produtores se refere ao preço do leite pago, este conceito desmotiva vários produtores, pois reflete em um sentimento de que não estão sendo recompensados como se deve, sendo que as despesas para se manter nesta produção é elevada. Neste viés, é necessário que exista um interesse maior do governo brasileiro em rever algumas diretrizes que possam proporcionar retorno mais significativo para esses produtores, desenvolvendo instrumentos voltados para a agricultura familiar com o objetivo de mantê-los na zuna rural e estimular a permanência dos membros da família na propriedade executando esta atividade.

Tais resultados foram importantes para mostrar que, independentemente do segmento do negócio exercido, o empreendedorismo está presente, dependendo do indivíduo que a exerce. Demonstrando que a atividade leiteira é um negócio como outro qualquer, que a propriedade rural se torna uma empresa com as mesmas funções executadas pelas grandes empresas tradicionais e que tal atividade possui um papel importante no desenvolvimento e na economia do país. Eles destacam que o produtor rural é sim um empreendedor e possuindo todas as 10 competências empreendedoras, mostrando o potencial que esse indivíduo/produtor tem perante qualquer profissional da área de negócios.

No que se refere as contribuições deste estudo, primeiramente aos os produtores rurais de leite, podese citar que ao desenvolver um panorama das competências que cada produtor possui relacionado ao seu potencial empreendedor, este estudo empírico retrata a importância que o desenvolvimento de cada uma das dez competências têm para a longevidade da propriedade rural, essencialmente ao desenvolvimento das competências que não obtiveram resultados satisfatórios e que necessitam ser analisadas caso à caso. Os resultados da pesquisa fornecem aos produtores um compilado de informações acerca das características das 
propriedades da região e de como esses produtores estão pensando e gerindo seus negócios. Essas contribuições se estendem não apenas aos produtores rurais de leite, mas aos produtores de distintas atividades rurais, uma vez que, o conjunto dessas competências empreendedoras são fundamentais independente da atividade principal da propriedade rural.

Em relação às contribuições para a comunidade científica, essa experiência empírica traz uma proposta metodológica que permite ser aplicada em outros segmentos agropecuários e setores relacionados ao agronegócio, adaptando os indicadores específicos a cada tipo de atividade. Estudos dessa natureza trazem contribuições significativas para o avanço da ciência, especialmente, no que concerne à valorização do empreendedorismo rural e das competências dos produtores rurais, muitas vezes esquecidos nos estudos sobre empreendedorismo, possibilitando um conjunto de resultados que enriquecem o arcabouço empírico deste campo de estudo ainda emergente.

Por outro lado, conscientizando os pesquisadores da importância de desenvolver estudos que demonstrem que o empreendedorismo é importante em todos os segmentos econômicos, até mesmo em propriedades rurais que, em sua maioria, são formadas por pequenos produtores familiares.

Pode-se, a partir deste estudo, sugerir novas pesquisas que envolvem a atividade leiteira não somente no estado do Rio Grande do Sul, possibilitando novos vieses para pesquisas com o interesse de aprimorar os benefícios que esta atividade proporciona no município que está vinculada, ou o descobrimento de soluções que ajudem a diminuir as dificuldades que ocorrem no processo de produção leiteira. Também, vale ressaltar que nesta atividade existe uma lacuna muito grande da falta de assessoria para os produtores rurais, pois os mesmos necessitam de um planejamento das funções que envolvem as atividades exercidas na propriedade, processos administrativos que relatem que não praticam, organização, controle, entre outros. Outra possibilidade de estudos futuros está na aplicação da proposta deste estudo para produtores rurais que desempenham outra atividade produtiva, como o cultivo de grãos ou suinocultura, por exemplo. Com o intuito de fazer um comparativo das competências empreendedoras encontradas em produtores de diferentes atividades.

\section{Referências}

Aguiar, T. (2013). Dê um start up na sua vida: reconheça suas melhores chances, siga seus instintos, o céu será o limite, Saraiva, São Paulo.

Bracht, D. E., Werlang, N. B. (2015). Competências empreendedoras: uma investigação com produtores rurais catarinenses. Revista de Empreendedorismo e Gestão de Pequenas Empresas, 4 (1), 101-124.

Caetano, B. (2014). Manual do empreendedorismo: 74 dicas para ser um empreendedor de sucesso, 2. ed., Gente, São Paulo.

Callado, A. C. (org.). (2011). Agronegócio, 3. ed., Atlas, São Paulo.

Castanheira, J. (2014). Vqd: vai que dá! Dez histórias de empreendedores que transformaram sonhos grandes em negócios de alto impacto, Portfoto/Penguim. 
Dutra, J. S. (2001). Conceitos e instrumentos para a gestão de pessoas na empresa moderna, Atlas, São Paulo.

Dornelas, J. C. A. (2012). Transformando ideias em negócios, 4. ed., Elsevier, Rio de Janeiro.

Embrapa, 2018. Centro Nacional de Pesquisa de Gado. Anuário do leite 2018. (Acesso Nov 2018). https:// www.embrapa.br/busca-de-noticias/-/noticia/36560390/anuario-do-leite-2018-e-lanca do-na-agroleite.

Endo, G. Y., Back, V. T., Hofer, E. (2018). Empreendedorismo rural: motivações para a diversificação de culturas na agricultura familiar do oeste de São Paulo. Revista Livre de Sustentabilidade e Empreendedorismo. $3(5), 5-21$.

Fleury, A., Fleury, M. T. L. (2004). Estratégias empresariais e formação de competências: um quebra-cabeça caleidoscópico da indústria brasileira, 3. ed, Atlas, São Paulo.

Ibge, 2017. Instituto brasileiro de geografia e estatísticas. (Acesso Dez 2018). https://www.ibge.gov.br/ estatisticas-novoportal/economicas/agricultura-e-pecuaria.html.

Lenzi, F. C. (2008). Os empreendedores corporativos nas empresas de grande porte: um estudo da associação entre tipos psicológicos e competências empreendedoras. Tese (Doutorado), Universidade de São Paulo, 2008. Disponível em: <www.teses.usp.br/teses/.../12/.../tese_fernando_lenzi_usp.pdf>. Acesso em: jun. 2018.

Muñoz, P., \& Kimmitt, J. (2019). Rural entrepreneurship in place: an integrated framework. Entrepreneurship and Regional Development. 31 (9-10), 842-873.

Müller, S., \& Korsgaard, S. (2018). Resources and bridging: the role of spatial context in rural entrepreneurship. Entrepreneurship and Regional Development. 30 (1-2), 224-255.

Moraes, G. H. S. M.; Iizuka, E. S., \& Pedro, M. (2018). Effects of Entrepreneurial Characteristics and University Environment on Entrepreneurial Intention. Revista Administração Contemporânea. 22 (2), 226-248.

Oliveira, A. B. B., Silva, R. A., Siqueira, E. S. \& Siqueira Filho, V. (2018). O empreendedorismo rural na cajucultura: um estudo de caso. HOLOS. 5, 116-139.

Reis, E. P., \& Armond, A. C. (2012). Empreendedorismo, IESDE Brasil S.A., Curitiba.

Resende, E. (2008). Competência, sucesso, felicidade: um roteiro prático para desenvolver competências destinado a executivos, líderes em geral, intelectuais, pais, professores, estudantes, empresários, políticos e profissionais liberais, Summus, São Paulo.

Richardson, R. J. (1999). Pesquisa social: métodos e técnicas, 2. ed., Atlas, São Paulo.

Sertek, P. (2007). Empreendedorismo, 4. ed., IBPEX, Curitiba. 
Triviños, A. N. S. (1987). Introdução à pesquisa em ciências sociais: a pesquisa qualitativa em educação, Atlas, São Paulo.

Vale, G. M. V., Correa, V. S., \& Reis, R. F. (2014). Motivações para o empreendedorismo: necessidade versus oportunidade?. Revista Administração Contemporânea. 18 (3), 311-327. 